\title{
SOBRE EL SIGNIFICADO DE MAWLÀ EN LA HISTORIA OMEYA DE AL-ANDALUS
}

\author{
Dolores OLIVER PÉREZ
}

Universidad de Valladolid

Queremos tratar aquí un problema difícil de resolver: la traducción de una voz que muy a menudo aparece en las fuentes y puede ser interpretada de formas muy distintas. Nos referimos a mawlà, término repetido por biógrafos e historiadores cuando desean marcar la relación que une a un determinado personaje con otro, o con un conjunto tribal y, sobre todo, con un soberano omeya, tipo este último que corresponde a la gran mayoría de los testimonios. Naturalmente, una de las soluciones por la que se suele optar es la de transcribir el término para que los lectores le den la interpretación que más les satisfaga. Esta postura que, he de confesar, es también la mía, puede acarrear problemas cuando aquellos que desconocen los valores atribuidos a dicho vocablo en el mundo islámico lo traducen por ciertas voces, como son la de liberto y las elegidas por Sánchez Albornoz: español, renegado y muladí, interpretaciones en consonancia con el pensamiento de un historiador para el que «los mawālī no eran ni árabes ni orientales» ${ }^{1}$.

Si bien en el pasado escribí un artículo sobre el significado de este término junto con el de árabe y muladí ${ }^{2}$, y lo hice basándome en el examen de todas las ocurrencias localizadas en un número importante de obras ${ }^{3}$, el que en la actualidad, con motivo de mi participación en el Diccionario de Autores y Obras Andalusíes, me haya visto obligada a transcribirlo o traducirlo, me mueve a volver sobre mi teoría para recordarla y completarla con nuevos datos y observaciones.

En estas páginas presentaremos pues un estudio de los significados asignados a mawlà en al-Andalus, en el período que se extiende desde la conquista hasta la caída del califato, y prestaremos una atención especial a toda mención de los

\footnotetext{
${ }^{1}$ Sánchez Albornoz, C., en El Islam de España y el Occidente, Madrid, 1974, p. 44, introduce esta frase tras señalar que, según Ibn al-Qütiyya, los guerreros de Balŷ eran 2.000 libertos. Sobre el texto al que alude, véase nota 35 de nuestro artículo citado infra. Para otras interpretaciones que da de mawälï, ibid., p. 149, nota 20.

2 «Una nueva interpretación de "árabe", "muladî" y "mawlà" como voces representativas de grupos sociales", en Proyección histórica de España en sus tres culturas, Valladolid, Junta de Castilla y León, 1993, III, 143-55.

${ }^{3}$ Cfr. ibid., donde se indican los títulos de todas las obras utilizadas, entre las que destacamos las siguientes: Ajbār Maŷmū'a (ed. E. Lafuente Alcántara, Madrid, 1867; cit. Ajbār); Ibn al-Qūtiyya, Ta'rỉj iftitāh al-Andalus (ed. Ribera, Madrid, 1926, cit. IQ); Ibn Hayyān, Kitāb al-Muqtabis, vols. III y V (cit. Muq.) e Ibn 'Id̄ārī, Kitāb al-Bayān al-mugrib, vols. I y II (ed. Colin- L. Provençal, Leiden, 1951, cit. Bayān).
}

Al-Qanțara XXII, 2 (2001) 321-344 
mawālì omeyas, grupo social cuyo análisis consideramos clave para entender la historia de al-Andalus. Asimismo, queremos adelantar que, si bien en nuestro suelo se documentan los tres tipos de parentesco señalados por Ibn Jaldūn, el que se realiza a nivel tribal y en la llamada "primera y segunda fase del Imperio», no tomamos como punto de partida el esquema del historiador tunecino. Al constatar que, en la primera mitad del siglo vIII, se establecieron de manera paralela vínculos a dos niveles, o sea, entre miembros de diferentes tribus y entre un determinado personaje o clan y los soberanos omeyas de Oriente, hemos creído conveniente elegir un enfoque diacrónico que permita mostrar el valor significativo de mawlà a lo largo de dos etapas históricas con características muy distintas.

\section{SignifiCAdo DE MAWLÀ DESDE EL AÑo 711 AL 755}

El examen de crónicas donde se narran sucesos acaecidos en al-Andalus desde la entrada de tropas musulmanas hasta el 755, en que 'Abd al-Raḥmān consigue restaurar la dinastía omeya, nos permite percibir dos tipos de wala según se haga referencia a una persona o colectividad.

El primero, documentado ya en tiempos preislámicos, es el establecido por un individuo a nivel tribal, único medio donde prima la solidaridad y la igualdad. En este caso, el mawlà - a menudo un árabe que se ve obligado a abandonar su antigua tribu por razones diversas ${ }^{4}$ - se convierte en un miembro más de la casa que le acoge y participa de sus privilegios y obligaciones, así como de la nobleza de su patrón. Según Ibn Jaldūn, el hombre no pertenece a la tribu en la que nace, sino a aquella cuya suerte decide compartir, y cuando se afilia a la nueva familia adopta su patronímico y borra de su memoria los sentimientos que le unen a su antigua agnación, por muy ilustre que sea, con el propósito de conseguir que, al cabo de algún tiempo, nadie recuerde su verdadero origen y se le confunda con los descendientes de la estirpe cuyo nombre lleva. Consecuencia de ello es que dentro de una tribu todos se consideren hijos y hermanos y no sea posible distinguir a los parientes consanguíneos de aquellos que en el pasado fueron adoptados 5 .

\footnotetext{
${ }^{4}$ Ibn Jaldūn destaca, como motivos frecuentes, el deseo de librarse de la esclavitud, muchas veces fruto de luchas tribales, y el evitar el pago del precio de la sangre por la muerte de un contríbulo. Como ejemplo de este último cuenta que 'Arfaŷa, de la tribu yemení de Azd, «habiendo matado a uno de los suyos buscó refugio en la tribu Bāhila (rama de Qays), adhiriéndose a ellos y destacando de tal forma que estuvo a punto de convertirse en su jefe». ( $C f r$. Ibn Jaldūn, Prolégomènes, texto árabe, ed. Quatremère, París, 1858, I, 239.2-11).

${ }^{5}$ Sobre estas particularidades, véase Ibn Jaldūn, ob. cit., I, 235.16-17; 238.11-19; 245.15-246.7; 332.16-18. Reproducción de palabras del Profeta indicativas de que el parentesco del walä' es equiparable al consanguíneo, en ibid., 246.1-3 y Bayān ed. L. Dozy (Leiden, 1848-51), Introd., 17.
} 
Las palabras del escritor tunecino coinciden con las conclusiones extraídas de nuestro estudio. El examen de textos parece indicar que, en la primera mitad del siglo VIII, dentro de las tribus andalusíes no se hacía distinción entre los miembros unidos por lazos de sangre y aquellos cuyos antepasados habían establecido un walà', ya fuera fruto de cualquier tipo de acuerdo (walā' al-muwālāt) o como resultado de una manumisión (walä' al-'itāqa); aspecto que, no dudamos, está íntimamente ligado a dos factores: la necesidad que tiene toda tribu de crecimiento, premisa imprescindible para adquirir poder; y el hecho de que los diferentes linajes tengan un alto número de hijos y éstos se unan en matrimonio con otros contríbulos, enlaces que traerán la conversión paulatina de muchos mawālì en auténticos deudos.

En lo que atañe en particular a la tribu Banū Umayya, si nos atenemos al $A j b \bar{a} r$ Maýmí 'a y, en concreto, a la parte escrita en el siglo viII por un sirio que entró en al-Andalus con Baly ${ }^{6}$, podemos ofrecer datos reveladores de que, a partir del 741, precisamente porque no goza de ninguna situación privilegiada, las relaciones entre sus miembros son las que acabamos de señalar. El cronista en un principio silencia su presencia, como si se tratase de un conjunto no digno de ser destacado y cuando, con motivo del anuncio de la llegada de Ibn Mu'āwiya, la saca a la luz, presenta a los omeyas acompañando o prestando su apoyo a las tribus mudaríes más poderosas como las de Fihr y Qays y exhibiendo siempre una actitud de humildad. Por ejemplo, besan la mano de alȘumayl (72.14); acuerdan no tomar decisiones sin consultar antes con el jefe qaysí (67.11) o prometen a éste último, en relación con la entrada del príncipe, no hacer nada que a él desagrade (69.13-4). Segundo, su autor da el mismo tratamiento a todos los miembros de dicha tribu, es decir, les denomina Banū Umayya y a la vez mawālì de 'Abd al-Rahmān, expresión que utiliza como sinónimo de la anterior para marcar los estrechos vínculos que les unían con el príncipe $^{7}$. Tercero, en repetidas ocasiones, destaca que la jefatura de los omeyas andalusíes estaba en manos de Abū 'Uțmān, 'Abd Allāh b. Jālid y Yūsuf b. Bujt, tres personajes que no parecen estar ligados a 'Abd al-Rạ̣mān por lazos sanguíneos ${ }^{8}$. Esto significa que, hasta la llegada de Ibn Mu'āwiya, los Banū

\footnotetext{
${ }^{6}$ En el estudio realizado sobre esta obra, que será publicado en Anaquel de Estudios Árabes, XI-XII, defendemos que las pp. del texto árabe 2.6-4.8 y 30.11-101.1 fueron redactadas por un sirio qaysí, tradicionista y guerrero, con la finalidad de perpetuar los principales sucesos en los que participaron las tropas que entraron con Balŷ.

${ }^{7}$ Este mismo tipo de expresión se localiza en otras obras, aunque de manera esporádica. $C f r$.: «sus mawāli, los Banū Umayya», en Fath al-Andalus (ed. L. Molina, FAH, 18, Madrid, 1994), 69.11 y Muq III, 35.1.

${ }^{8}$ Sobre el origen de estos personajes, véase Fierro, M., «Familias del Ta' rỉj Iffitāh hl al-Andalus de Ibn al-Qūtiyya», EOBA, IV (1990), 52, 55 (n. 42 y 51), e ibid., «Los mawali de 'Abd alRaḥmān I», Al-Qantara, XX (1999), 81 (n. 23$), 85$ (n. $\left.{ }^{\circ} 37\right)$ y 86 (n. $\left.{ }^{\circ} 41\right)$.
} 
Umayya eligen de manera democrática a sus dirigentes, y lo hacen atendiendo a su capacidad y no a su ascendencia, lo que no hubiera sucedido si se distinguiesen dos tipos de parentesco, como sucede cuando se constituye un Estado. Cuarto y último, el análisis de los diversos testimonios de mawlà pone en evidencia que sólo la traducción de «pariente» resulta adecuada para todos ellos. Es cierto que no faltan ejemplos donde podría traducirse por «señor» y «cliente», como las frases en las que se señala que 'Abd al-Raḥmān es mawlà de Abū 'Uțān y 'Abd Allāh b. Jālid (Ajbār, 73.15) y viceversa, pero también existen otras donde ninguna de dichas interpretaciones encaja. Nos referimos al hecho de que para su autor los quinientos omeyas que le ayudan a derrotar a Yūsuf son mawālì de Ibn Mu'āwiya, y no es posible aceptar que entre ellos no existieran parientes consanguíneos, además de conocer que se cita a Habỉb b. 'Abd al-Malik al-Qurašì, descendiente del califa 'Umar (87.12).

En suma, el estudio de este término a la vista de las observaciones que sobre las tribus hace Ibn Jaldūn, inclina a apoyar que la caída de la dinastía omeya en Oriente y el paso del poder a manos 'abbāsíes hizo que los antiguos Banū Umayya se convirtieran en una tribu más y se dejara de distinguir a los parientes que lo eran por sangre o por walä'. Los omeyas andalusíes entre los que no faltaban descendientes de los soberanos orientales, bien por línea directa, bien como fruto de uniones matrimoniales, se consideraban situados en un mismo plano y se miraban entre ellos como simples primos o parientes.

\subsection{Mawālī de los Banū Fulān «rama de...», «linajes emparentados con...»}

En esta primera etapa, también parece usarse mawlà con el propósito de marcar las relaciones que se dan entre los diversos linajes de un conjunto tribal y aquel que en un momento histórico ha conseguido destacar sobre el resto. Estamos ante un sentido del que habla Ibn Jaldūn ${ }^{9}$ al señalar como hecho natural la existencia dentro de una gran cabila de dos 'așabiyyas: la que une a todos los clanes con un antepasado común y la que liga a los miembros de cada uno de ellos en particular; y al explicar cómo las diferentes familias que la forman, para reforzar su parentesco y aumentar su poder, aceptan el mando de la más poderosa y se sitúan frente a ella como ramas colaterales.

\footnotetext{
${ }^{9}$ Sobre este tipo de relaciones, véase ob. cit. I, 239.14-17; 253.4-7; 299.10-300.5. y, en particular, el texto árabe de Ibn Jaldūn que reproduce Slane junto con su traducción en Notices et extraits des manuscrits de la Bibliotheque imperiale. Prolégomènes historiques de Ibn Khaldun, París, 1985, I, 275, texto que no se registra en la ed. de París aquí citada, pero sí en la de Bulaq.
} 
El análisis de textos andalusíes permite percibir este tipo de walä' y distinguir dentro de él dos categorías o niveles en función de que el jefe de la estirpe dominante sea un simple caudillo tribal o ejerza además un poder político.

1.2.1. Cuando nos encontramos ante la primera situación, las tribus hermanas se convierten en mawālì de los Banū Fulān, es decir, en «ramas» de aquella que, perteneciendo al mismo tronco, se juzga superior pero, al enfocarse la relación desde una perspectiva tribal, todas las familias se colocan en el mismo plano y sus miembros siguen dándose el tratamiento de «primos».

En nuestra opinión, los cronistas andalusíes emplean mawāli en este sentido cuando desconocen o no consideran necesario enumerar a los diferentes linajes de una importante tribu, y es dicho valor y no el de «clientes» el que debe asignarse a frases como la del Ajbār: «en Córdoba existían familias nobles de mawālì de los Banû Hāšim, de los Banū Fihr y de las cabilas de Qurayš ${ }^{10}$ que, por haber gozado de gran preponderancia en tiempos de Yūsuf, tras su caída le incitan a rebelarse». El examen de la terminología empleada por el autor de este texto mueve a apoyar que su intención no es marcar que fueron precisamente grupos de «clientes» de las mencionadas tribus los que trataron de recobrar su pasado prestigio, sino las diversas familias nobles que se movían bajo el patronímico común de Banu Hāšim, Banū Fihr y Qurayš. El mismo significado es el que también aplicamos a otros textos, por ejemplo, cuando se dice (p. 95.10) que en el año 140 (=757) «entraron en al-Andalus gentes de los Banū Umayya y de sus mawālī», o sea, que pertenecían al linaje del príncipe y a ramas emparentadas ${ }^{11}$.

1.2.2. El segundo tipo de walä', que también surge de manera natural y sin que el vínculo requiera necesariamente el previo establecimiento de un pacto, se distingue del anterior porque el dirigente de la tribu ejerce un cargo político, ya sea el de simple gobernador o el de monarca de un Estado soberano. En dicho caso, los clanes que comparten el mismo ascendiente se sitúan a un nivel inferior y sus miembros, aunque sean parientes consanguíneos, pasan a conceptuarse como mawālī en el sentido de «familias subordinadas a aquella que se ha alzado con la jefatura».

\footnotetext{
${ }^{10}$ El texto reza (95.11-2): buyūtāt min mawālì Banī Hāšim wa-Banī Fihr wa- qabā'il Qurayš. Para su interpretación se ha de recordar lo que Ibn Jaldūn (ob. cit., 242.20-243.4) entiende por bayt: «familia o linaje de abolengo que cuenta entre sus antepasados con varios hombres de rango elevado y célebres, siendo las cualidades de estos últimos y el profundo respeto que han inspirado lo que hace que los descendientes de dicho linaje gocen en su comunidad de alta consideración».

${ }^{11}$ Cfr. Ajbär, 95. 10 donde se dice literalmente: nās min Banì Umayya wa-mawālì-him. En el Fath (95.7) y en el Bayān (II, 49.2), al aludir al mismo hecho, no se hace mención de mawāli. Sólo se indica que en el año 140 de la hégira entraron rî̀ăl min Bani Umayya.
} 
La diferencia entre estas dos clases de «parentesco» se detecta en un curioso texto de Ibn al-Qūtiyya, en el que se reproducen las palabras dirigidas por Muhamad b. Mūsà (de la tribu de los Banū Mūsà, rama de Gāfiq), a los Banū 'Abd al-Rahmān, nietos del gobernador de al-Andalus 'Abd Allāh al-Gāfiqĩ: «mezclémenos unos con otros y formemos una sola familia, porque si somos vuestros mawāli, como pretendéis, somos de los vuestros (minkum), y si somos árabes somos primos (ban̄u 'ammi-kum)». Es decir, si os veis como linaje que en el pasado, al ascender de rango, nos reunió bajo su dirección, somos parientes vuestros; si os consideráis una simple tribu árabe, somos iguales ${ }^{12}$.

El mismo valor significativo ha de aplicarse a mawālì cuando se usa para marcar el vínculo que une a los miembros de tribus pertenecientes a un mismo tronco con aquel que, gozando de un cargo político, ejerce la jefatura de la más poderosa. Para su documentación en crónicas andalusíes contamos con varios relatos del $A j b \bar{a} r$ en los que, de manera repetida, se señala que «los Banū Umayya eran mawālì de Yūsuf al-Fihrì», y con un texto de Ibn al-Qūtiyya, donde el cronista cordobés indica, quizá con sorpresa o ironía, que Yūsuf «llamaba a los Banū Umayya sus mawālì» ${ }^{13}$, denominación que, partiendo de la teoría expuesta, resulta natural. A nuestro entender, el nombramiento de Yūsuf como gobernador de al-Andalus, que tiene lugar cuando los omeyas han sido derrocados por los 'abbāsíes y han perdido su preponderancia, va a convertirle en cabeza visible de las diversas tribus de Qurayš y, consecuentemente, todas ellas pasan a subordinarse a los Fihr. Aunque 'Abd al-Raḥmān era primo de Yūsuf, y en su clan no faltarían parientes consanguíneos de otros fihríes, el cambio de jefatura dentro de los Qurayš de al-Andalus hará que los omeyas se vean obligados a situarse en un plano inferior y a aceptar, como «rama» de Fihr, la denominación de mawālì de Yūsuf.

\footnotetext{
${ }^{12}$ Cfr., 76. 6-9. No compartimos la interpretación que hace de este texto Fierro (art. cit., AlQantara XX, p. 89, nota 124) de que los Banū Mūsà aprovechan el walä' establecido por su antepasado para reivindicar que son árabes. Ibn al-Qūtịya dice bien claro que Muhammad b. Mūsà pertenecía a «un prestigioso linaje árabe (min bayt min al-'arab), el de los Banū Mūsà, cuya nisba era Gāfiq» (75.10) y no indica que establecieran un walä' con dicho gobernador. Es muy posible que, al ascender Muhammad de categoría y, sobre todo, al convertirse en ministro, los Banū 'Abd al-Raḥmān se vanagloriaran de que en el pasado, cuando su antecesor directo era walì de al-Andalus, los Banū Mūsà se habían considerado mawālī «rama colateral». Incluso en el caso de que en dicha época (730-32) hubieran cambiado su nisba por la de la tribu hermana de más prestigio, la de Gāfiq, se habrían convertido en Gāfiqíes de pleno derecho. Significativo es también que los Banū 'Abd alRaḥmān le dieran las gracias y «se casaran unos con otros», práctica muy usual entre linajes de un mismo tronco.

${ }^{13} A j b a \bar{a}, 70.7 / 72 ; 71.5,6 / 73 ; 76.7 / 76 ;$ IQ, 21.13.
} 
Dentro del estudio de este walā' se ha de destacar un segundo aspecto. Cuando se produce dicho cambio, los miembros de la tribus emparentadas optan por dos posturas: la de seguir manteniendo su identidad, aunque ello suponga situarse en un nivel inferior, o la de integrarse completamente en la familia más poderosa, lo que obliga a los mawālì a cambiar sus filiaciones genealógicas ${ }^{14}$. Esta segunda opción es la que, no dudamos, asumieron un alto número de linajes de Qurayš cuando los omeyas se alzaron como soberanos de Oriente, quizá por los grandes beneficios que se obtienen al ligarse a un monarca. Frente a las muchas familias qurayšíes que se conformaron con ser mawāli de los omeyas, otras decidieron olvidar a sus ancestros directos para convertirse en auténticos Banū Umayya.

El mencionado fenómeno se detecta con claridad cuando fijamos nuestra mirada en textos donde se informa de cuántos y quiénes son los componentes de un ejército y reflexionamos sobre datos como los siguientes: Kultūm sale de Siria con 30.00 hombres, 10.000 de la flor de los Banū Umayya y 20.000 árabes ${ }^{15}$; Balŷ entra en al-Andalus con 2.000 omeyas y 8.000 árabes ${ }^{16} \mathrm{y}$, poco después, bajo el gobierno de Yūsuf, en al-Andalus sólo quedan 500 Banū Umayya (Ajbār 70.11). Las primeras cifras, 10.000 y 2.000, en nuestra opinión muy altas, revelan que muchos qurayšíes optaron por adquirir esa denominación que les presentaba emparentados a los califas orientales. Por otro lado, la notable disminución que más tarde experimenta dicha tribu muestra que en el 750, al caer la dinastía, la mayor parte de esos 2.000 guerreros vuelven a recobrar su identidad y a tomar el nombre de aquellos clanes a los que en realidad pertenecían. También es indicativo de que, al ser elegido gobernador Yūsuf al-Fihrī, quizá por darse prerrogativas propias de un Estado, algunos antiguos Banū Umayya, en particular los que gozaban de cargos oficiales en Córdoba, pasasen a identificarse con los Fihr, frente a esos 500 que se mantuvieron fieles y pre-

\footnotetext{
${ }^{14}$ Sobre este aspecto habla también Ibn Jaldūn (299.11-300.2) cuando indica que «si la familia es muy poderosa absorbe a las demás, concentrando en sí misma todas las 'așabiyya-s».

${ }^{15}$ Bayān, II, 30.8-9 y I. 55.8 (ambos tomados de Ibn Qațān): «10.000 de la espina dorsal (ṣulb) de los Banū Umayya y 20.000 árabes»; IQ (14.15-15.1): «10.000 de... los Banū Umayya y 20.000 de linajes nobles árabes». (Los editores de su obra suplen el espacio en blanco por mawâlì. A nuestro entender su lugar podría también ser ocupado por el vocablo que registra el Bayān, aunque en ambos casos el significado sería «linajes de los Banū Umayya»).

${ }^{16}$ Según Ibn al-Qūtiyya (15. 13-14) «de los 10.000 que entran con Balŷ, 2.000 eran mawālì y 8.000 árabes». Curiosamente, el mismo autor poco después, al referirse al mismo grupo para señalar su enfrentamiento con 'Abd al-Raḥmān b. 'Alqama, dice que «Balŷ sale a su encuentro con 10.000 que eran omeyas y sirios (16.12: min al-umawiyyin wa-l-šāmiyyinn), expresión que repite en 17.6, 8. Asimismo, al mencionar a Artobás en el comienzo de su obra y, refiriéndose de nuevo a los compañeros de Balŷ, nos dice que "más tarde hablará de lo que le sucedió a Artobás con las tropas sirias que vinieron a España con omeyas y árabes» (5.5: ma' al-umawiyyīn wa-l-'arab).
} 
firieron conservar su antiguo patronímico. Naturalmente, los Banū Umayya volverán a multiplicarse al hacerse Ibn Mu'āwiya con la jefatura de los diversos clanes de Qurayš.

\section{SIGNIFICADO DE MAWLÀ BAJO LA SOBERANÍA OMEYA ANDALUSÍ}

Cuando 'Abd al-Raḥmān I, después de vencer a Yūsuf, decide establecer en al-Andalus un Estado centralizado y una monarquía hereditaria, va a poner todos los medios para conseguir que su familia sea la más fuerte y poderosa, premisa imprescindible si desea mantenerse en el trono. Su primer paso, tal y como señalan los cronistas, consistirá en reunir junto a él a los que considera auténticos deudos, los Banū Umayya, a la vez que tratará de captar para su causa a los miembros de esas ramas colaterales que habían vuelto a recobrar su antigua identidad o a aliarse a los Fihr. Después llamará a su lado a los parientes árabes que se encontraban en Oriente o en el norte de África y a aquellos de raza beréber que estaban unidos a él por sangre a través de su madre o por haber establecido lazos con sus antepasados, como es el caso de los Banū Wānsūs. Finalmente, intentará reforzar su familia mediante la creación de nuevos vínculos, ya sea por manumisión o por contrato, política que traerá un aumento notable de mawāli.

Ahora bien, en este período somos testigos de dos fenómenos que incidirán de manera directa en el uso y significado del termino mawlà. Uno responde al hecho de encontrarnos ante lo que Ibn Jaldūn llama la «primera fase del Imperio», caracterizada por la existencia de una sociedad organizada jerárquicamente, y por ello muy distinta de la tribal. El otro, quizá particular de alAndalus, es fruto del enfrentamiento entre grupos que defienden dos concepciones diferentes de vida, la estatal y la tribal cuya consecuencia será que el vocablo mawlà, como representativo de la primera, adquiera claras connotaciones políticas.

Los diversos aspectos que se han de tener presente en el estudio de mawlà en esta etapa nos obligan a comenzar con observaciones sobre los cambios experimentados por la familia omeya a medida que se desarrolla un nuevo tipo de gobierno y su reflejo en la terminología que la define, para después detenernos a examinar otras cuestiones consideradas de interés como son: las diferentes categorías de mawālī, su etnia, el carácter hereditario del walā' y el análisis de mawlà como vocablo que define a las gentes fieles al Estado frente a árabe, que personifica a los rebeldes. 


\subsection{La familia de los soberanos: Los «qurayš» y los «mawālī»}

Pensamos que a lo largo de la etapa omeya se fue consolidando en alAndalus ese modelo de sociedad estatal que Ibn Jaldūn considera propio de «un imperio», y una de cuyas características es que los miembros de la familia reinante no gocen de la misma nobleza. Según el escritor tunecino, la existencia de jerarquías hace que se sienta la necesidad de distinguir a los hijos y hermanos de monarcas del resto de parientes y de diferenciar dentro de estos últimos a los antiguos deudos, cuyo origen exacto se desconoce, de aquellos que han realizado un pacto reciente.

Cuando estamos atentos a sus palabras y fijamos la mirada en las fuentes históricas y, en particular, en la terminología empleada por los cronistas, nos damos cuenta de que los cambios por él señalados también se dieron en al-Andalus aunque no precisamente bajo el primer emir omeya. Los datos recogidos sugieren la existencia de tres etapas distintas.

2.1.1. En la primera, la correspondiente al gobierno de 'Abd al-Rahmän, el análisis de vocablos y narraciones pone de manifiesto que la conquista del emirato no supuso un cambio de actitud de Ibn Mu'āwiya hacia sus mawālī, postura que ha de considerarse natural, pues sólo un hombre soberbio e ingrato desprecia a los compañeros que le han ayudado a ascender de posición y se sitúa por encima de ellos. Para el autor del Ajbār que escribe en el siglo vIII, la familia del príncipe está compuesta por los Banū Umayya (91.10, 92.11, 95.10) o «sus mawālī» $(91.5,9)$, expresiones que junto a la de al-Umayya se localizan también, aunque en menor medida, en crónicas de fecha posterior ${ }^{17}$. De manera paralela su comportamiento coincide con el que, según Ibn Jaldūn, es propio de los jefes tribales que con la ayuda de sus parientes llegan a convertirse en soberanos e inauguran la llamada «primera fase del Imperio», fase cuyas características describe, entre otras, con las siguientes palabras: en ella el príncipe «no se atribuye prerrogativas porque la 'așabiyya o solidaridad tribal que le ha permitido conseguir sus propósitos, sigue viva en él y le obliga a limitar sus ambiciones» $\mathrm{y}$ «a tratar a los miembros de su tribu de la misma forma que lo hacía cuando las circunstancias le eran adversas», es decir, «como hermanos e hijos»; asimismo «se apoya en su clan para mantenerse en el poder y reprimir las revueltas», a la vez que «recompensa su esfuerzo, compartiendo con ellos

${ }^{17}$ Frente al uso común de «sus mawālī», repetido por los diversos historiadores (IQ, 31.10, 11, 12; 33.4; Bayān II, 51.15, etc.), en al-Nuwayrī (Kitāb Nihāyat-al-'arab, I, ed. y trad. Gaspar Remiro, Granada, 1917) encontramos Banū Umayya (I, 10.13) y al-Umayya (58.18; registrándose también esta última en el Fath al-Andalus, 104.11). 
la administración del nuevo Estado y nombrándolos visires, gobernadores y recaudadores de impuestos» ${ }^{18}$.

2.1.2. Con la muerte del príncipe y, fundamentalmente, bajo el gobierno de 'Abd al-Raḥmān II se inicia una segunda etapa marcada por el uso de una nueva terminología (mawqib «cortejo», dīwān, «registro» ahl al-jidma «funcionarios de la administración», etc.), reflejo de que en este período empiezan a desarrollarse los órganos de gobierno propios de un Estado soberano, que irán acompañados del nacimiento de una incipiente vida cortesana, y reveladores también de que en estos momentos no se sabe cómo denominar a los considerados parientes de los monarcas. Ahora se deja de emplear Banū Umayya para designar a los descendientes de miembros de la primitiva tribu, se registran algunos testimonios de mawāli seguidos del nombre de un soberano ${ }^{19}$, a los que se suman un mínimo de ocurrencias de al-umawiyyūn ${ }^{20}$, pero es el término jāsșa, «aristocracia», el que claramente se destaca como definitorio de la familia de los monarcas ${ }^{21}$. Es decir, ante la falta de voces concretas, los cronistas se limitan a informar que la jāsșa de los soberanos estaba integrada por «sus mawālì » y por hombres con la nisba al-Quraši ${ }^{22}$.

2.1.3. Es a partir de la muerte de 'Abd al-Rahmān II, cuando se localiza la expresión «los mawālì» como representativa de un grupo social que con dicho nombre se ha institucionalizado ${ }^{23}$. En algunas ocasiones, al hablar de los que forman parte de la corte de los soberanos o de sus tropas, los cronistas eligen la frase «los qurayš y los mawālì» ${ }^{24}$, en otras, al designar a los componentes de un ejercito presentan a los mawāli como grupo que se distingue del llamado $\hat{y}$ und o hašam ${ }^{25}$; en unas terceras, cuando describen las solemnes audiencias

${ }^{18}$ Las frases que aquí reproducimos se repiten con idénticas o similares palabras en $o b$. cit., 315.3-6; 330. 3-7; 332. 14-18 y 333.11-13.

${ }^{19} \mathrm{IQ}, 96.10 ; 69,11 ;$ Ajbār, 130.12, 139.12, 15; al-Nuwayrī, 33.8.

${ }^{20}$ De momento sólo hemos encontrado un testimonio en al-Nuwayrī, 37.18.

${ }^{21}$ IQ, 56.15, 60.9, 65.12; Ajbār, 124.14; 125.4,8; 128.1, 129.12; Bayān, II, 61.9, 79.5. E. Lafuente traduce $(113,115$ y 116) las tres últimas ocurrencias por «sus familiares»; la correspondiente a $124.14 / 113$, que forma parte de una frase cuya traducción literal es «sus hijos y el resto de su jāșșa», por «sus amigos».

${ }^{22} \mathrm{El}$ autor de $A j b \bar{a} r$, además de informar de los personajes con la nisba al-Qurašì, que formaban parte de su jāṣsa (127.16-128.8), ofrece un relato donde describe a al-Hakam I, rodeado de su jāṣṣa (129.12) para después especificar que son sus mawālì (130.12) los únicos que en ese momento le acompañan.

${ }^{23}$ En la obra de Ibn al-Qūtiyya encontramos la expresión «los mawālī» $(65.12,67.9)$ al hablar de etapas precedentes, uso que, a nuestro entender, no responde a una realidad, sino al deseo de emplear el término vigente en su época para definir a los parientes de soberanos.

${ }^{24}$ IQ, 82.2, 102.1; Bayān, II, 158.9,10; Muq. III, 34.13-14, 111.3,9; Anales Palatinos del Califa de Córdoba al-Hakam II, por 'Isà al-Rāzī, Madrid, 1967, p. 236.

${ }^{25} \mathrm{IQ}, 71.2$, 102.2; Bayān, II, 169.12, 208.5; Muq. III,104.14. 
celebradas por 'Abd al-Raḥmān III y al-Ḥakam II, y enumeran a los personajes que participan, constatamos que parte de ellos aparecen integrados en dos colectivos bajo los nombres respectivos de los qurays̄ y los mawāli ${ }^{26}$. En esta etapa también se pueden encontrar algunas ocurrencias de omeyas, pero sólo en textos con características muy particulares y no alusivos a habitantes de la capital. De momento, únicamente hemos hallado testimonios en Ibn Hayyān, todos ellos en narraciones de sucesos acaecidos en Sevilla. En su Muqtabis III, al reproducir el relato de un escritor local referente a la guerra civil que estalló en dicha ciudad en tiempos de 'Abd Allāh (pp. 67-83), da los nombres de los individuos que no tomaron parte en los enfrentamientos y que pertenecían respectivamente a los qurayš y a los umawiyyūn (68.14), para después aplicar la expresión «los mawālī» $(70.8,73.10,18)$ y al-umawiyyūn $(75.2,19)$ a unos mismos hombres. En su Muqtabis V, en una narración tomada de al-Rāzī, al aludir también a hechos sucedidos en Sevilla, en los que participó Ibn alQūtiyya, define a ciertos individuos que se unieron a las tropas del sultán como «los sirios y los omeyas», expresión que, curiosamente, gustaba repetir el mencionado cronista cordobés ${ }^{27}$.

En lo que respecta, en particular, a la época del califato creemos que, a partir de "Abd al-Raḥmān III se dio un cambio de actitud hacia «los parientes», quizá porque ahora nos encontramos en cierto modo en lo que Ibn Jaldūn llama «la segunda fase del Imperio» ${ }^{28}$, fase en la que «el soberano decide gobernar autocráticamente y aislarse en su gloria». Según el escritor tunecino, «el monarca no soporta que sus mawālì le traten con familiaridad e insolencia y le miren como se mira a los de la propia tribu, por lo que se apoyará en clientes de raza distinta, siendo éstos y no los miembros de la familia los que ocupen los principales cargos y los que gocen de mayor privanza» ${ }^{29}$. El examen de textos de este período revela que, si bien los califas siguen nombrando a qurays̄ies

\footnotetext{
${ }^{26}$ Muq. V, 278.4,15/306; E. Lévi Provençal y E. García Gómez, Una Crónica anónima de 'Abd al-Rahmmān al-Nāsir, Madrid-Granada, 1950, p. 30/138 [n. ${ }^{\circ}$ 2]; Anales Palatinos, 118 [n. ${ }^{\circ} 82$ ]; 153 [127]; 171 [143]; 224 [198]. En 239 [203] sólo se menciona a los principales mawālì cordobeses pero no a los Qurayš; en 273 [237], al hablar de la ceremonia que organiza el califa al-Hakam con motivo de la ruptura del ayuno, se indica que, antes de pasar a la cámara, los miembros de Qurayš y el resto de los Banū Umayya, junto con los Hasaníes, esperaron en el Bayt al-wizāra mientras que los mawālì lo hicieron en el Balāṭ al-Rịh.

${ }^{27} \mathrm{La}$ expresión «omeyas y sirios» (al-umawiyyūn wa-l-šāmiyyūn) sólo la hemos localizado en IQ $(16.12,17.6,8,19.8)$, siendo este testimonio (Muq. V, 71.10-11/64.13-14) el único donde volvemos a encontrar a ambos grupos, aunque citados en un orden inverso y con palabras distintas ( $\min$ al-šāmì wa-l-umawī).

${ }^{28}$ Ob. cit., 315.6-8; 330-8-19.

${ }^{29}$ Ibid., 333.19-334.7.
} 
y mawāli para altos cargos de la administración ${ }^{30}$, surge una nueva clientela que se situará por encima de la familia ${ }^{31}$. Asimismo, se constata que dentro de los parientes, más que distinguirse categorías en función de su origen, se tendrá en cuenta si desempeñan o no un papel en el gobierno.

En suma, podemos decir que hacia mediados del siglo Ix cambia el valor de algunos términos. Banū Umayya, antes representativo del grupo clánico que, establecido en al-Andalus, acogió al emir, ya sólo se utiliza cuando se alude a la dinastía reinante. Qurayš, que en la primera mitad del siglo vIII se empleaba para designar a los diversos linajes que procedían del mismo tronco que los omeyas, es el término elegido para definir a los descendientes directos de soberanos ${ }^{32}$ frente a los mawālì, grupo en el que se integraban lo que podemos concebir como «parientes de categoría inferior». En lo que respecta a las expresiones al-umayya y al-umawiyyūn pensamos que, al menos en la corte cordobesa, dejan de utilizarse para señalar al colectivo formado por los antiguos mawāli, aunque algunos personajes añadirán a su nombre la nisba al-Umawī, en un deseo de marcar su vinculación a la casa reinante.

\subsection{Los mawālī: sus diversas categorías}

Si bien aquí defendemos que el grupo social denominado los mawālì representaba en al-Andalus una aristocracia compuesta por familias que estaban o se sentían emparentadas a los soberanos omeyas, dentro de ellos es posible distinguir diversas categorías ${ }^{33}$.

2.2.1. En la más baja se encuentran todos aquellos que han establecido un wală' con miembros de la dinastía andalusí, situándose en el mismo nivel los que lo hicieron como fruto de una manumisión o de manera voluntaria. Si nos atenemos a Ibn Jaldūn los integrantes de este primer grupo no se considerarían

\footnotetext{
${ }^{30}$ En las listas que trae el Muqtabis $\mathrm{V}$ (pp. 65, 67, 88, 94, 117, 146, 166, etc.), con la mención de los nombres de los ministros, encontramos bastantes individuos con la nisba de al-Qurašì y, sobre todo, mawlà-s descendientes de los antiguos Banū Umayya.

${ }^{31}$ Significativas son frases como las de $A j b \bar{a} r$ (155): «tomó por ministros a personas incapaces; ofendió a los nobles elevando a gentes villanas y despreciables, como el (esclavo) Naŷda, el de Hïra, y sus compañeros de la misma ralea»; «Dio a Naŷda el mando del ejército y le confió los más importantes asuntos, mientras que ordenó a los nobles de los ŷunds, a los jefes del ejército y a los ministros que se supeditaran a él y acataran sus órdenes».

${ }^{32}$ De esta denominación se ha de excluir a los hijos y hermanos que, como tales, son presentados sin agregarse a sus nombres la nisba al-Qurašì, reservada a sus descendientes.

${ }^{33}$ Sobre la situación de los clientes véase, en particular, el capítulo de Ibn Jaldūn (pp. 332-334), cuyo título es: «Sobre la situación de los mawālì y los muștana 'ūn en el imperio».
} 
auténticos parientes porque, aunque trataran de ocultar su origen, no lo conseguirían a excepción de algunos que empezasen a destacar cuando hubieran transcurrido varias generaciones. Las características propias de un Estado y el hecho de que los escritores se preocupen de consignar el nombre del soberano al que se han ligado los personajes más relevantes les impediría hacerse pasar por viejos deudos.

2.2.2. Una escala superior ocupan los antiguos Banū Umayya y sus descendientes, que se estiman parientes de pleno derecho, aunque algunos no estuvieran unidos por lazos sanguíneos, sino a través de un wală' establecido con califas orientales. La posición social de éstos frente a los anteriores se detecta al examinar las crónicas andalusíes y percibir que son familias pertenecientes a este grupo las que gozan de mayor prestigio y las que desempeñan bajo los sucesivos soberanos cargos territoriales, administrativos y militares.

2.2.3. En la etapa califal se va a efectuar una nueva distinción, en este caso no basada en el origen sino en el hecho de que contribuyan o no al buen funcionamiento del Estado. Si en las narraciones referentes al emirato los mawāli constituyen un grupo homogéneo que goza de la privanza de los soberanos y que forma parte de sus ejércitos y de su gobierno, algo muy diferente percibimos al examinar textos donde se describen las audiencias solemnes que celebran 'Abd al-Rahmān III y al-Ḥakam II. Al prestar atención al orden en que entran los diversos colectivos o al lugar donde se sientan, que siempre va a depender de su categoría, constatamos que los representantes de la familia apenas disfrutan de relevancia o prestigio. En dichas solemnidades los primeros en entrar y sentarse en el lugar preferente son los hermanos e hijos; a continuación los visires; en tercer lugar los altos funcionarios palatinos a los que a menudo se suman jefes de ejército o de policía, y sólo después serán recibidos los qurayš y los mawālī, a los que seguirán, en último lugar, los cadíes, alfaquíes y ulemas. Ahora bien, al fijarnos en los nombres de los ministros y altos dignatarios, constatamos que en su gran mayoría o llevan la nisba al-Qurašī, o pertenecen a esas familias de mawlà-s que durante varias generaciones han prestado sus servicios a los omeyas. Esto sugiere que los «parientes» ya no juegan el mismo papel que cuando el Estado estaba en su primera etapa de existencia, quizá porque el crecimiento desmesurado de la familia y las particularidades de este período han obligado a diferenciar dos grupos: por un lado encontramos una aristocracia ociosa de «parientes» que disfrutan de determinadas prebendas y dan brillo a la corte, pero que no es valorada por no contribuir con su esfuerzo a la prosperidad de la nación; por otro, en una escala muy superior, están esos mawāliz, a los que alude Ibn Jaldūn cuando dice que «a la nobleza nacida del parentesco se 
suma la que adquieren cuando ejercen importantes cargos al lado de los príncipes» ${ }^{34}$.

2.2.4. Finalmente, queremos exponer nuestra sospecha de que en Oriente y Occidente se dio la denominación de mawlà a individuos que sin establecer vínculo alguno se integran en la familia a través de mujeres. Nos referimos a un tipo de «parentesco» del que indirectamente hablan los cronistas al informar que determinados personajes se convirtieron en mawāli de soberanos, bien por ser hermanos de sus esposas, bien por ser hijos de las mismas pero fruto de previos matrimonios. Un ejemplo del primer caso lo tenemos en un tal Fā'iq o Rā'iq, hermano de Șubh, ŷâriya del califa al-Hakam II, que recibe la denominación de mawlà de al-Hakam y ejerce, como tío materno del heredero, cargos en la administración califal ${ }^{35}$. Para documentar el segundo recordaremos a al-Ḥamriyya, esposa de Abū Ŷa 'far al-Manșūr, cuyo hijo Ṭayfūr, nacido de un matrimonio anterior, fue llamado, según Ibn Hazm, mawlà amìr al-mu'minīna, por ser hermano del propio Mahdí, aunque sólo por parte de madre ${ }^{36}$. Nos encontramos pues ante «parientes políticos», cuyo estudio lo consideramos de interés porque supone, desde la perspectiva del parentesco occidental, la existencia de mawlà-s que, como descendientes de los anteriores, entrarán en la categoría de «primos carnales» de hijos de monarcas.

\subsection{Los mawālī: su pertenencia étnica}

La pertenencia étnica de los mawālī es un aspecto que últimamente se viene discutiendo y sobre el que queremos dar nuestra opinión, por considerar que no es posible hablar de su etnia sin distinguir etapas históricas, dinastías y regiones.

En primer lugar, los mawālì andalusíes no representan un grupo social análogo al de los orientales y, en concreto, al de los iraníes que se identifican con indígenas y conversos. Cuando los árabes, bajo el período de 'Umar (634-44), se apoderaron de territorios que se encontraban en un estadio de civilización muy superior a la de los pueblos nómadas, su inexperiencia les obligó a poner en manos de autóctonos convertidos al Islam la dirección de esos quehaceres o trabajos que ellos nunca habían realizado, y a reclutar entre sus pobladores a la mayor parte de los funcionarios. Un siglo más tarde los abbasíes se apoyarán

${ }^{34}$ Ob. cit., 245. 25-8.

${ }^{35}$ Cfr. Marín, M., «Una vida de mujer: Șubḥ», EOBA, VII, 434-45.

${ }^{36} \mathrm{Ibn}$ Hazm, Naqt al-'arūs (texto árabe de Seybold y traducción de Seco de Lucena, Valencia, 1974), 160/95. 
en mawlà-s persas, primero para derrocar a los omeyas, después para construir un Imperio ajeno a sus propias tradiciones. Consecuencia de ello será el nacimiento de una aristocracia de musulmanes iraníes que, por ser definidos como «los mawālì», ha hecho que dicho nombre se asocie a conversos de raza no árabe, sin pensar en la posibilidad de que hubiera «clientes» con características distintas.

A nuestro entender no existen razones históricas que obligen a equiparar a los mawālì 'abbāsíes con los propios del imperio omeya. Cuando Mu'āwiya se hace con el poder en Oriente crea un modelo de Estado que, frente al de los Banū 'Abbās, recibe la denominación de «árabe», tanto por sus características como por estar ubicado en una región donde habitan tribus árabes y gentes de la misma raza que, por haber adoptado la cultura y la forma de vida imperantes bajo período bizantino, están capacitadas para ayudar a los soberanos a la creación de un nuevo tipo de régimen ${ }^{37}$. El que los omeyas se apoyen en mawālì musulmanes de raza árabe, además de hacerlo en bizantinos, no sólo resulta natural sino que puede fácilmente documentarse. A pesar de las muchas dificultades que existen cuando se intenta descubrir a los ancestros de unos hombres que al unirse a una nueva familia tratan de ocultar sus raíces, el análisis de obras históricas y biográficas proporciona múltiples ejemplos. Si nos centramos en los jefes de los ejércitos que entraron en al-Andalus vemos que, tras señalarse el nombre del soberano con el que ellos o sus antepasados establecieron el walā', se suma un «se dice», en el que entre otras hipótesis se sugiere su pertenencia a una determinada tribu árabe. Por ejemplo, de Musà b. Nuṣayr (mawlà de 'Abd al-Azīz b. Marwān) se cuenta que «era un árabe de la tribu de Lajm o de la de Bakr b. Wā'il» ${ }^{38}$, tesis en consonancia con las palabras de Ibn Jaldūn cuando, en un capítulo dedicado a los mawālì, dice que «los Banū Umayya de Oriente se apoyaron en sus guerras y en la administración de sus provincias en hombres de raza árabe», y cita entre otros a Mūsà b. Nuṣayr ${ }^{39}$. Asimismo conocemos que Mugīt,

\footnotetext{
${ }^{37}$ A pesar de que esta primera afirmación resulta muy fácil de documentar, repetiremos algunas palabras de Ibn Hazm reproducidas en el Bayān, I, 39.10, ss., que consideramos muy significativas: «El imperio de los Banū Marwān de Oriente fue, a pesar de sus defectos, un imperio árabe (dawla 'arabiyya); sus monarcas continuaron viviendo en las propiedades donde residían antes de convertirse en califas, no se preocupaban en acumular riquezas (...) ni exigían el tratamiento de señor, ni pedían demostraciones serviles». En contraposición (pp. 40. 1, ss): «el imperio de los Banū 'Abbās no fue árabe (dawlatu-hum a' ŷamiyya)», siendo bajo su dominio cuando «desapareció el tipo de organización administrativa de los árabes (dawāwīn al-'arab) y pasó a manos de los $a^{\text {'ŷăm }}$ de Jurasán la dirección del gobierno».

${ }^{38}$ Ajbār, 3.14; al-Maqqarī (ed. Dozy, Analectes, Amsterdam, 1967), I, 156.15-18; Bayān, I, 39.18; II, 22.19.

${ }^{39}$ Ob. cit., 331.10-11. Poco después dirá que los 'abbāsíes se apoyaron en los a 'ŷām.
} 
el conquistador de Córdoba (mawlà de 'Abd al-Malik b. Marwān y educado con el futuro califa al-Walīd), es descrito como «árabe gassānī que había sido capturado por los bizantinos» ${ }^{40}$. Incluso no faltan los que califican a Țāriq b. Ziyād, de «árabe de la tribu de Șadif», aunque generalmente se acepte era beréber ${ }^{41}$. Ahora bien, lo que nos interesa no es conocer la etnia de los que dirigieron los ejércitos de la conquista ni tampoco la de los muchos mawālì de «supuesta» ascendencia árabe que apoyaron a 'Abd al-Raḥmān, sino el hecho de que los historiadores nunca hubieran reproducido dichos rumores si fuera cierto que entre los mawlà-s omeyas no había árabes.

En lo que respecta a los andalusíes, se ha de tener presente que los conquistadores, entre los que se cuentan muchos mawlà-s con experiencia estatal, no precisan del elemento indígena para alcanzar sus propósitos que, por otro lado, no coinciden con los de esos antepasados que iniciaron la conquista de Oriente. La historia de al-Andalus nos muestra que a lo largo de los primeros cincuenta años, árabes y beréberes traslucen su deseo de vivir según sus viejas tradiciones en vez de adoptar el tipo de régimen o las instituciones propias del mundo occidental; es decir, las tribus árabes se dedican a luchar entre ellas para alcanzar un mayor poder, o a formar alianzas con el propósito de enfrentarse a sus enemigos beréberes o de derrocar a los gobernadores impuestos por los soberanos de Oriente. En este período es natural que admitieran en sus tribus al elemento indígena, cristiano o musulmán, pero de igual forma las diversas familias yemeníes y muḍaríes tratarían de destacar entre ellas y de vencer a sus antagonistas ancestrales mediante la adopción de nuevos parientes árabes a nivel individual o colectivo. También es significativo que 'Abd al-Raḥmān I tuviera un trato muy parcial e injusto hacia sus mawālì beréberes, aunque algunos portasen su misma sangre, y no sucediese lo mismo con los denominados Ban̄u Umayya, posiblemente porque al estimarse árabe sentiría inclinación hacia los que consideraba de su misma etnia. En suma, el análisis de obras históricas y biográficas lleva a apoyar la existencia de mawālī de diferentes etnias y religiones, y por ello no equiparables a los iraníes.

\subsection{El walā' como vínculo hereditario y de libre aceptación}

Otro punto que consideramos de interés es el hecho de que el walä' se herede, es decir, los descendientes de aquel que se vinculó a la familia omeya serán

${ }^{40}$ Al-Maqqarī, ob. cit., II, 6. 24-5, citando como fuente a al-Hiŷāāì.

${ }^{41}$ Ajbār, 6.13; Bayān, I, 43.7-9; II, 5.4, 11-12; al-Maqqarī, I, 159.20. 
mawlà-s de los sucesivos monarcas que asuman el poder, particularidad claramente reflejada en las palabras que dirige Yūsuf b. Basī a los eunucos, cuando éstos le piden que les acompañe con sus tropas para entregar el trono al príncipe Muhammad en vez de hacerlo a su hermano 'Abd Allāh: «nosotros somos mawāli de aquel que entre en palacio y se convierta en rey» ${ }^{42}$. Este carácter hereditario impide precisar si un determinado personaje ha establecido el pacto con ese monarca al que los cronistas o biógrafos le vinculan o lo han hecho sus antepasados, y parece explicar el porqué no siempre coinciden al señalar de qué soberano se es mawlà.

Otro aspecto íntimamente ligado al anterior es que los descendientes de un mawlà tienen la opción de aceptar o rechazar el wală', pues de la misma forma que se ingresa en una familia es posible abandonarla. $\mathrm{Al}$ hacer un recorrido por la historia de al-Andalus vemos que dentro de destacados linajes de mawāli existen miembros que deciden romper sus lazos con los omeyas para pasar a formar parte de la oposición y recuperar la antigua nisba tribal. Como ejemplo de beréberes podemos citar a los Banū 1-Jalī' de Tāqurunnāo a los Banū Wānsūs ${ }^{43}$, mawlà-s de 'Abd al-Rahmān I y antes de califas orientales, con descendientes que se alzaron contra el régimen. En lo que respecta a estirpes árabes tenemos a los Banū 'Āṣim, cuyo antepasado el taqafi ‘'̄ṣim al-Uryān ayudó a Ibn Mu'āwiya a derrotar a Yūsuf. El estudio realizado por Fierro sobre esta familia pone de manifiesto que, si bien algunos descendientes están muy interesados en ser considerados mawlà-s, otros deciden desligarse de los omeyas y recobrar la nisba de al-Taqafí ${ }^{44}$.

\subsection{Matices especiales que asume el término mawlà y sus consecuencias}

La lectura de fuentes andalusíes parece indicar que la implantación por parte de 'Abd al-Rahmān de un sistema de gobierno contrario a los principios que por tradición habían apoyado los árabes va a traer la oposición de estos últimos $\mathrm{y}$, consecuentemente, el nacimiento de lo que podemos llamar dos posturas políticas, posturas que los cronistas tratarán de reflejar dando un nuevo valor a los vocablos mawlà y árabe, para convertirlos en símbolo de la fidelidad al

$42 \mathrm{IQ}, 80.9$.

${ }^{43}$ Sobre estas familias, véase respectivamente, De Felipe, H., Identidad y onomástica de los beréberes de al-Andalus, Madrid, CSIC, 1997, 157-61 y 230-8.

44 Fierro, M., «Los Banū 'Āṣim al-Ṭaqafi, antepasados de Ibn Zubayr», Al-Qanțara VII (1986), 53-84. 
Estado o de la rebeldía. Es decir, árabe toma el sentido de «beduino» y pasa a definir a los que, perteneciendo a dicha etnia, tratan de derribar a la dinastía reinante y se niegan a obedecer a toda autoridad no elegida por ellos mismos. Frente al anterior, mawlà será voz representativa de las gentes que defienden el tipo de régimen establecido por los omeyas.

La existencia de estos dos grupos, que tienen su propia escala de valores, va a traer claras consecuencias, sobre todo porque los cronistas (con la única excepción de los autores del Ajbār) pertenecen al partido del gobierno. Ellos se sienten obligados a convencer al pueblo de que el tipo de sociedad en el que se integran los mawlà-s responde a la necesidad de adaptarse a los nuevos tiempos y debe ser aceptado como el más perfecto y el único al que Dios da su asentimiento. De manera paralela, tratan de poner de manifiesto que es la impiedad y la ignorancia la que ha movido a hombres de su misma etnia a pensar y actuar según principios que sólo tenían cabida en tiempos preislámicos.

Esta postura parcial, que se trasluce en sus obras, va incidir en el uso de mawlà, uso que, a nuestro entender, presenta las siguientes características:

2.5.1. La defensa de una sociedad que insiste en definirse como «no beduina» hace que los historiadores tengan mucho cuidado en no utilizar la expresión mawlà-s árabes ${ }^{45}$, o en no mencionar que los soberanos pertenecen a dicha etnia. En la misma línea, cuando hablan de gentes que trabajan para el gobierno, no adjuntan tras su nombre nisbas de carácter tribal, con una curiosa excepción, la de los cadíes cuya misión es juzgar a los súbditos y dirigir la oración y, en menor medida, la de otros jurisconsultos ${ }^{46}$. Es posible que la explicación de este hecho se deba a que nunca se dejó de sentir que eran los árabes los más capacitados para juzgar según la ley de Dios, por conservar el espíritu del pasado en toda su pureza y no haberse dejado corromper por los bienes materiales, lo que no sucedía con la aristocracia cortesana nacida en el seno del lujo y de la opulencia. Cuando escuchamos a al-Jušanī hablar de «los jueces de Córdoba» creemos captar su admiración por esos hombres sencillos, con nisba tribal, que rechazan reiteradamente el cargo ofrecido por los soberanos, que no temen actuar contra los mismos monarcas y echarles en cara sus injusticias y

\footnotetext{
${ }^{45} \mathrm{El}$ único testimonio encontrado se registra en el Muq. III (68.13), en el relato antes mencionado sobre la fitna que tiene lugar en Sevilla. Aparece en una frase donde se dice que apoyan al sultán hombres sinceros «que eran Qurayš y mawālì de los anteriores, tanto árabes como beréberes» (min Qurayš wa-mawälï-him min al-'arab wa-l-baräbira), contexto en el que claramente designa una etnia. Hemos de señalar también la no localización de texto alguno donde se indique que un soberano omeya es «árabe».

${ }^{46} \mathrm{El}$ examen de las listas de cargos gubernamentales que trae el Muqtabis $\mathrm{V}$ muestra que la nisba tribal no se adscribe a ministro alguno, pero sí a personajes que se registran bajo el epígrafe de alfaquíes, así como a otros que ocupan los cargos de jefe de la policía, zalmedina y zabazoque.
} 
que muestran su deseo de abandonar el bullicio de la capital y refugiarse en la paz del campo ${ }^{47}$. También es posible que se acepte por tradición que sean árabes los encargados de la judicatura, como sucedió en el comienzo del Estado omeya cuando el juez supremo de Córdoba era denominado $q \bar{a} d \underline{\imath} l-\hat{y} u n d^{48}$. Lo cierto es que, si nos atenemos a dicha obra, son muchos los jueces árabes y escasísimos los mawālì, dándose también el caso de que el nombramiento de un mawlà para ese cargo sólo sea aceptado por el pueblo con la condición de que no dirija la oración ${ }^{49}$.

2.5.2. Otra norma de los historiadores es silenciar la etnia de «los parientes», aunque únicamente lo harán en un segundo período, cuando consideren ya consolidado el tipo de gobierno instaurado por los Omeyas. La mención de mawālì beréberes es frecuente en una primera etapa histórica pero, a partir de la muerte de 'Abd al-Rahmān, el origen étnico deja de ser un factor digno de ser destacado. Quizá ello se deba al deseo de minimizar la aportación beréber e hispana a la creación del imperio, pero también puede responder al pensamiento de que estamos ante un linaje de origen oriental y todos los miembros de la familia deben identificarse con él.

2.5.3. En el estudio de este término se ha de examinar también otro aspecto que impide conocer si un determinado personaje es mawlà o «árabe». Nos referimos al hecho de que los cronistas atribuyan el calificativo de mawlà a personajes que no lo son, o sea, a individuos destacados que trabajan para los omeyas pero sin perder su filiación genealógica. A nuestro entender, los soberanos andalusíes, de la misma forma que se sirvieron de grupos tribales, caracterizados por su bravura y arrojo para domeñar a los rebeldes de turno, creemos que no dudaron en conceder altos cargos a «árabes», en cuya fidelidad confiaban y que sobresalían por su honradez y valía. Naturalmente, si en el primer caso constatamos un cambio en la terminología que les define, es decir, los grupos clánicos denominados «árabes», al someterse y pasar a luchar en las filas del gobierno, se convierten en «tropas de las circunscripciones militares» ( $\hat{y} u n d)$ o bien en «defensores de la comunidad» (ahl $\left.a l-\hat{y} a m \bar{a}^{`} a\right)$, «gentes fieles» (ahl $a l-t \bar{a}^{‘} a$ ), «los perfectos o piadosos» (al-mutqanūn), etc., también es posible

\footnotetext{
${ }^{47}$ Cfr. Ribera, J., Historia de los Jueces de Córdoba por Aljoxani, Madrid, 1914. Como ejemplo de jueces que gustan vivir en el campo y realizar faenas humildes, véanse $61 / 75 ; 85 / 105$; 87/107; 109/132.

${ }^{48}$ Muchos de los jueces a los que dedica un capítulo al-Jušanī son árabes sirios de los $\hat{y} u n d-s$ ( $c f r .27 / 35 ; 30 / 38 ; 45 / 55 ; 51 / 62 ; 71 / 89 ; 77 / 96 ; 79 / 98 ; 95 / 116 ; 191 / 200$ ), lo que hace pensar en la pervivencia de la costumbre implantada al comienzo del emirato.

${ }^{49}$ Cfr. 117-8/144. Un segundo mawlà omeya lo encontramos en $185 / 225$. La abundancia de cadíes árabes con nisba tribal se constata con una mirada al índice.
} 
que, en el segundo, den el título de mawlà-s a individuos que no se consideran parte de la familia. Uno de ellos pudo muy bien ser Tammām b. 'Alqama, del que sabemos por los biógrafos que un antepasado suyo fue mawlà de un árabe taqafĭ al que denominaban 'Abd al-Raḥmān b. Umm al-Ḥakam, por ser su madre hermana del primer soberano omeya, Mu'āwiya b. Abī Sufyān ${ }^{50}$. Cuando le encontramos en al-Andalus vemos que, según el $A j b \bar{a} r$, es un miembro destacado de la tribu de Taqîf que ha decidido apoyar a Ibn Mu'āwiya y que, como tal, «acompaña a los Banū Umayya». Si la lectura del Ajbār, donde en ningún momento se dice que él o sus descendientes sean mawlà-s, sugiere que estamos ante un taqafi $\bar{i}^{51}$, una idea muy distinta transmite Ibn al-Qūtiyya, que le aplica el calificativo de mawlă ${ }^{52}$, y nunca su nisba tribal, quizá por considerar que su comportamiento no es el propio de un beduino ${ }^{53}$.

2.5.4. Un último hecho que se ha de destacar como resultado de estas dos posturas políticas es el desprecio de los árabes hacia aquellos que olvidan sus raíces para aliarse con el poder, y en particular hacia esos mawlä-s de la corte califal, gentes inútiles y sin otra preocupación que disfrutar de una vida holgada y de lujo a la sombra de la dinastía. No es extraño, por ello, que en el Ajbār, obra de árabes sirios, se utilice el relato del recibimiento que hace 'Ubayd Allāh b. al-Ḥabḥāb, gobernador de Ifrīqiya, a 'Uqbā al-Salūlī (25-7/36-8), para criticar la actitud de esos hombres que se vinculan a la casa reinante con el único propósito de adquirir riquezas y honores y que, por ejercer cargos gubernamentales, se creen superiores al elemento tribal. En ella se cuenta que sus hijos, «que eran unos soberbios», se muestran muy ofendidos al ver que su padre sienta en el trono a un «beduino» ('arabī), menospreciando de esta forma a los Qurayš, y pone en boca de 'Ubayd Allāh palabras del Profeta y de Abū Bakr al-Ṣiddīq, maldiciendo a los que reniegan de su nasab para atribuirse un parentesco que no les corresponde y enorgullecerse de pertenecer a una familia extraña.

\footnotetext{
${ }^{50}$ Ibn al-Abbār, Al-Hulla al-siyarā' ' (ed. Dozy, Notices..., Leiden, 1947-51), 77.

${ }^{51}$ En la misma se indica (103.16) que el príncipe 'Abd al-Rahmān envía a Toledo, para sofocar una rebelión, a su mawlà Badr y a Tammān, prueba de que el segundo seguía sin ser considerado mawlà del entonces soberano. Las mismas palabras se reproducen en el Bayān (II, 53.1), obra en la que, sin embargo, al mencionar la rebelión de Abū Șabbāḥ (53.23), se señala que el príncipe mandó para negociar con él a su mawlà Tammām.

${ }^{52}$ Cuando el príncipe le pregunta su nombre, su respuesta es, según Ibn al-Qūṭiyya (24.8): «tu mawlà Tammām»; para el autor del Ajbār (75.6): «Tammān».

${ }^{53}$ Para entender la postura de Ibn al-Qūtiyya se ha de tener presente el uso que hace del término árabe y, en particular, las palabras que pone en boca de 'Abd al-Rahmān I (31.13-14) con la finalidad de que sus mawāli beréberes se las transmitan a los beréberes que han decidido unirse a los árabes contra el príncipe: «Hacerles ver que si los árabes vencen y el Estado Omeya se derrum$b a$ ellos no podrán sobrevivir a su lado».
} 


\section{3. ÚLTIMAS OBSERVACIONES A MODO DE CONCLUSIÓN}

Estamos ante un grupo humano cuyo estudio resulta muy complejo al ser muchos los factores que han de tenerse en cuenta: el período histórico que se está narrando; el modelo de estructura en la que se integran; la región en la que viven; su uso a nivel individual o colectivo; la fecha de redacción de la obra; la postura política del cronista, así como otros muchos de los que no hemos hablado por no haber sido objeto primordial de nuestro estudio.

Aunque con esto queramos decir que el tema de los mawālì no lo damos por cerrado y esperamos poder en el futuro continuar y completar su investigación, hemos creído conveniente concluir con una ojeada al problema expuesto al comienzo de este artículo para dar nuestra opinión personal sobre la traducción de mawlà y agregar observaciones en torno a la etnia de los que integran dicho grupo social, sin olvidarnos de incluir algunas de las muchas interrogantes que el estudio de ambos aspectos nos ha planteado.

En primer lugar nos preguntamos por qué los traductores se limitan a verter mawlà por «patrón», «cliente» o «liberto» a pesar de que los diccionarios ofrecen otras muchas definiciones. Por un lado dan las de aliado, defensor, amigo, compañero, etc., representativas de actitudes o comportamientos que van intrínsecamente unidos al wala ${ }^{\prime}$; por otro, las de señor y pariente, con un carácter muy distinto y a las que es preciso prestar atención especial porque, pensamos, en muchos casos podrían ocupar el lugar de las generalmente elegidas en las traducciones.

Comenzando con la de «señor», es sabido que estamos ante el sentido aplicado a los testimonios que forman parte de la fórmula ya mawlayya «oh mi señor», equivalente a $y \bar{a}$ sayyidī, y que también se asocia dicha acepción con la de «patrón». Ahora bien, lo que queremos sugerir es la posibilidad de que sea adecuada para otro tipo de ocurrencias como, por ejemplo, aquellas en la que al-mawālì va seguido de un calificativo designando una región o una etnia, y no de un genitivo posterior que marca la vinculación a determinada persona o tribu. Las expresiones min al-mawāli l-šāmiyyīn o min al-mawālì l-barbar referidas a un individuo o grupo podrían interpretarse como «señores» o «jefes» sirios o beréberes, aunque frente a sayyid se sugiera, además, su pertenencia a una familia emparentada con los omeyas. En apoyo de este significado, que se encuentra íntimamente ligado al de «linaje» o «rama colateral», señalaremos que Ibn al-Qūtiyya, cuando habla de los preparativos para traer a la Península a Ibn Mu'āwiya, utiliza la primera expresión (24.5) como definitoria de aquellos que se declararon a favor de su causa y que, en el Ajbār, reciben la deno- 
minación de Banū Umayya. Esto supone que no estamos ante «clientes sirios», sino frente a «señores» 0 «jefes de linajes» vinculados por sangre o wala ' a los Banū Umayya. En cuanto a la segunda, aplicada al mismo Ibn al-Qūtiyya, no creemos que se esté indicando que sus antepasados fueron simples clientes beréberes, sino «destacados personajes» 0 «señores nobles» que emparentaron con los omeyas ${ }^{54}$. Es decir, no podemos desechar la posibilidad de que en determinadas ocurrencias mawāli se utilice en sentido de «señor», quizá en un deseo de destacar el alto rango que se adquiere al realizarse el wala ' con un soberano ${ }^{55}$.

En lo que respecta a la traducción de «liberto» y «cliente», las más repetidas, estimamos que no siempre son adecuadas, y por ello no deben emplearse como norma para todas las ocurrencias de un determinado trabajo; la primera sólo ha de elegirse cuando se especifique que alguien acaba de ser manumitido, mientras que la segunda precisa ir acompañada de una breve nota que explique el sentido dado a la clientela en el mundo islámico, porque su uso indiscriminado puede llevar al error de catalogar como «clientes» a auténticos deudos. Por otro lado, el uso reiterado de dichas traducciones proporciona una idea falsa de la historia de los omeyas andalusíes, al poner de manifiesto que fueron «libertos y clientes» los responsables de la creación de su imperio. Lo lógico sería pensar que eran mawālī «señores omeyas» los que dirigieron los ejércitos de la conquista; los que con su esfuerzo consiguieron que la dinastía volviera a restaurarse en al-Andalus; los que, perteneciendo a prestigiosas familias, ocuparon los puestos de mayor responsabilidad y ayudaron a los monarcas a defender y consolidar su Estado, y muchos de los cronistas y literatos que se preocuparon de difundir la historia de «la familia» y de contribuir al desarrollo de la civilización, escritores como el «mawlà» Ibn Hazm que, no olvidemos, llevan la nisba al-Umawī «el omeya» 56 .

Finalmente, consideramos que la de «pariente» es la más correcta y la única adecuada para un alto número de testimonios, sobre todo si se tiene presente que dicho vocablo se asocia en Occidente con vínculos sanguíneos, pero no a partir de la misma escala de valores. Si nosotros no hacemos distinción entre

${ }^{54}$ Sobre esta expresión, aplicada a Ibn al-Qūtiyya, véase Fierro, M., «Árabes, beréberes y muladíes», en EOBA, VII, 53 y nota 58.

${ }^{55}$ Quizá deba aplicarse el mismo sentido a otro tipo de frases; por ejemplo, las utilizadas por Ibn al-Qūtiyya cuando describe a al-Ṣumayl como «jefe de los árabes de al-Andalus» (sayyid al'arab bi-l-Andalus) y, de manera paralela, da la denominación de sādāt al-mawālì bi-l-Andalus «jefes de grandes señores omeyas» (?) a personajes que en $A j b \bar{a} r$ (66.10) llevan la bandera de los Banū Umayya $(66.11,87.14)$ y son concebidos como «caudillos ( $\left.r{ }^{\prime} a s \bar{a}^{\prime}\right)$ de los Banū Umayya».

${ }^{56}$ Cfr. Maqqarī, I, 512.10 . 
la descendencia por vía paterna o materna, los árabes, al tener sólo en cuenta el linaje del padre, silencian la ascendencia femenina, lo que puede suponer la existencia de muchos parientes nuestros que no lo son en el ámbito islámico. Es decir, los hijos de dos hermanas no serán primos, los de hijas de califas casadas con mawlà-s no serán qurayš, y no tendrán sangre árabe los de mujeres árabes esposadas con hombres de otra etnia.

Por otro lado, se ha de recordar que estamos ante un mundo donde prima la poligamia y en el que los califas se casan con esclavas y los mawālì con mujeres emparentadas a los soberanos, siendo muy frecuente que esclavas y esposas sean de origen hispano ${ }^{57}$. Lo que interesa no es destacar por ejemplo que alNāṣir desposó a la hermana de su esclavo Naŷda ${ }^{58}$, sino la existencia de mawlà-s e incluso de siervos cuyos descendientes tendrán al menos una parte de sangre idéntica a la de monarcas que ejerzan el poder. Asimismo, a la hora de interpretar mawālī por «cliente», se ha de tener en cuenta que la proliferación de matrimonios entre las distintas familias que dicen compartir un mismo ascendente haría que con el tiempo muchos mawlà-s se convirtieran en «parientes», desde nuestra propia valoración del parentesco.

En suma, resulta muy difícil conocer cuantos mawālì están unidos a los descendientes de su patrón por lazos sanguíneos y descubrir quienes pueden recibir el calificativo de hispanogodos, beréberes o árabes. Aunque al expurgar un alto número de obras es posible empezar a distinguir a las familias que patrilinealmente pertenecen a las diferentes etnias, no es factible hablar en términos absolutos de parentesco o de un mismo origen étnico. Lo único cierto es que los mawãli andalusíes se consideraban parientes de la casa reinante, es decir «omeyas», y eran en su mayoría hombres con distintos aportes étnicos, al igual que los soberanos a los que servían, por cuyas venas, de todos es sabido, corría sangre árabe, beréber e hispana.

\section{RESUMEN}

En este artículo tratamos de abordar un problema de difícil solución: la forma de traducir el término mawlà, cuyo significado no es el mismo en todas las regiones y etapas históricas. Estudiamos el uso que de este vocablo y de su plural se hizo en al-Andalus

${ }^{57}$ Cfr. Ibn Hazm, ob. cit., 160-1/94-96, los textos encabezados por los epígrafes: «Los que a pesar de pertenecer a noble familia y elevada alcurnia se desposaron con mujeres de clase baja» y «Personas vulgares que se desposaron con mujeres emparentadas con califas».

${ }^{58}$ Ibid., 160/95. 
desde la época de la conquista hasta la caída de califato de Córdoba, sumando observaciones personales relativas a los tipos de walä' que se establecieron, al papel desempeñado por el grupo social denominado «los mawālī» y a factores muy diversos que ayudan a interpretar correctamente dicho nombre.

\section{ABSTRACT}

In this paper we address a problem with no easy solution: the translation of the term mawlà, whose meaning differs from region to region and is subject to change over time. We study the use of this word in al-Andalus from the period of the Conquest to the fall of the Caliphate of Cordova, adding some personal observations concerning the types of wal $\bar{a}$, the role played by the social group called «the mawālì and many other factors that help to establish the correct interpretation of this word. 